\title{
Group I Metabotropic Glutamate Receptors in the Monkey Striatum: Subsynaptic Association with Glutamatergic and Dopaminergic Afferents
}

\author{
Maryse Paquet and Yoland Smith \\ Yerkes National Primate Research Center and Department of Neurology, Emory University, Atlanta, Georgia 30322
}

Group I metabotropic glutamate receptors (mGluRs) are involved in long-term synaptic plasticity and neuroprotection in the striatum, but the specific role(s) of mGluR1 and mGluR5 remain poorly understood. In this study, we used electron-microscopic immunocytochemistry to compare the pattern of subsynaptic and subcellular distribution of mGluR1a and mGluR5 in relation to putative glutamatergic and dopaminergic inputs to the monkey striatum.

At the light-microscopic level, both group I mGluRs are expressed in the striatal neuropil. In addition, numerous perikarya of striatal output neurons are immunostained for mGluR5, but much less frequently for mGluR1a. At the electron-microscopic level, immunoreactivity for both receptor subtypes is primarily expressed postsynaptically in dendrites and spines, although presynaptic mGluR1a labeling of glutamatergic thalamostriatal boutons and, less frequently, dopaminergic and corticostriatal terminals is also seen. In contrast to mGluR1a, mGluR5 immunoreactivity is rarely encountered presynaptically. In postsynaptic elements, $40-70 \%$ of immunoreactivity for both receptor subtypes is expressed intracellularly, whereas $30-60 \%$ is apposed to the plasma membrane. More than $80 \%$ of the labeling apposed to the plasma membrane is extrasynaptic. The remaining $20 \%$ is located at the edges of putative glutamatergic synapses or in the active zone of symmetric synapses. In mGluR5-, but not mGluR1a-immunostained sections, $\sim 70 \%$ of dopaminergic symmetric synapses are labeled perisynaptically.

These data emphasize the differential pattern of subsynaptic localization of the two group I mGluRs and provide various presynaptic and postsynaptic sites whereby mGluR1 and mGluR5 could mediate different, but complementary, effects on glutamatergic and dopaminergic transmission in the primate striatum.

Key words: caudate nucleus; putamen; extrasynaptic receptors; immunogold; corticostriatal; thalamostriatal; nigrostriatal

\section{Introduction}

Glutamate, the major excitatory neurotransmitter in the CNS, activates both ionotropic and metabotropic glutamate receptors (mGluRs). Eight subtypes of mGluRs have been cloned (mGluR1 to -8) and subdivided into three groups on the basis of their amino acid sequence homology, second messenger systems, and pharmacology. Group I receptors (mGluR1 and -5) are linked to the activation of phospholipase $\mathrm{C}$ and generally mediate postsynaptic excitatory effects, whereas group II (mGluR2 and -3) and group III (mGluR4, -6, -7, and -8) receptors are negatively coupled to adenylyl cyclase and generally mediate presynaptic inhibitory influences on neurotransmitter release (Nakanishi, 1994; Conn and Pin, 1997)

The basal ganglia are enriched in the three groups of mGluRs, but current knowledge of their synaptic localization and functions remains limited. In the striatum, group I mGluRs are primarily expressed in projection neurons and subpopulations of

\footnotetext{
Received February 3, 2003; revised June 17, 2003; accepted June 23, 2003.

This work was supported by National Institutes of Health Grants R01 NS37423 and RR00165. We acknowledge Jean-Francois Pare and Maney Mazloom for technical assistance. We also thank Frank Kiernan for photography.

Correspondence should be addressed to Dr. Yoland Smith, Yerkes National Primate Research Center, Emory University, 954 Gatewood Road Northeast, Atlanta, GA 30322. E-mail:yolands@rmy.emory.edu.

Copyright $\odot 2003$ Society for Neuroscience $\quad 0270-6474 / 03 / 237659-11 \$ 15.00 / 0$
}

interneurons, whereas group II and III mGluRs are mostly localized presynaptically on glutamatergic terminals (Testa et al., 1994, 1995, 1998; Kinoshita et al., 1998; Bradley et al., 1999; Kosinki et al., 1999; Tamaru et al., 2001; Corti et al., 2002). In addition to their preponderance in postsynaptic striatal neurons, activation of group I mGluRs also mediates presynaptic effects on GABA and dopamine release in the rat striatum (Verma and Moghaddam, 1998; Bruton et al., 1999; Battaglia et al., 2001). Furthermore, postsynaptic functional interactions between group I mGluRs and dopamine receptors are necessary for the induction of long-term depression (LTD) of corticostriatal synapses (Gubellini et al., 2001; Sung et al., 2001), a phenomenon that has also been seen in the rat prefrontal cortex (Otani et al., 1999). If such is the case, one might expect postsynaptic group I mGluRs and dopamine receptors to be related to each other in striatal neurons.

Until recently, the two group I mGluR subtypes were thought to mediate similar effects in the CNS. However, the use of highly specific antagonists revealed significant functional differences between mGluR1 and mGluR5 whenever they are coexpressed in various basal ganglia nuclei and the hippocampus (Valenti et al., 2002). For instance, activation of mGluR5, but not mGluR1, potentiates NMDA responses in striatal projection neurons (Pisani 
et al., 2001), whereas activation of mGluR1, but not mGluR5, presynaptically modulates GABAergic transmission and mediates neuroprotective effects against NMDA toxicity (Battaglia et al., 2001). Whether these diverse functions rely on a differential pattern of subsynaptic targeting of the two group I mGluRs in striatal neurons remains to be established. To further characterize this issue, we performed a detailed comparative electronmicroscopic analysis of the subcellular and subsynaptic localization of mGluRla and mGluR5 in the monkey striatum.

Preliminary data have been presented in abstract form ( $\mathrm{Pa}-$ quet and Smith, 2000).

\section{Materials and Methods}

\section{Single group I mGluR immunostaining}

Animals, perfusion, and preparation of tissue. A total of four adult rhesus monkeys (Macaca mulatta) was used for this part of the study. Animals were deeply anesthetized with an overdose of pentobarbital $(100 \mathrm{mg} / \mathrm{kg}$, i.v.) and perfused transcardially with cold oxygenated Ringer's solution followed by a fixative containing $4 \%$ paraformaldehyde and $0.1-0.5 \%$ glutaraldehyde in phosphate buffer (PB) $(0.1 \mathrm{~m} ; \mathrm{pH} 7.4)$. The perfusion and killing procedures used in this study are in accordance with the National Institutes of Health Guide for the Care and Use of Laboratory Animals and have been approved by the Institutional Animal Care and Use Committee at Emory University. After perfusion, the brains were removed from the skull, blocked in 10 -mm-thick slabs, postfixed at $4^{\circ} \mathrm{C}$ in $4 \%$ paraformaldehyde for $2-6 \mathrm{hr}$, and cut into $60-\mu \mathrm{m}$-thick transverse sections with a vibrating microtome. Sections were collected in cold PBS $(0.01 \mathrm{M} ; \mathrm{pH} 7.4)$ and stored at $4^{\circ} \mathrm{C}$ until additional processing. All of the sections processed for immunohistochemistry were put in a $1 \%$ sodium borohydride solution for 20 min and washed in PBS before incubation with antibodies.

Primary antisera. Two commercially available affinity-purified rabbit polyclonal antisera raised against the synthetic C-terminal peptides representing different amino acid sequences of mGluR1a (PNVTYASVILRDYKQSSSTL; Chemicon, Temecula, CA) and mGluR5a/b (KSSPKYDTLIIRDYTNSSSSL; Upstate Biotechnology, Lake Placid, NY) were used in this study. In immunoblot analysis of rat brain microsomes or rabbit brain extracts, both antibodies labeled a single band with an estimated molecular weight of $140 \mathrm{kDa}$ (Ferraguti et al., 1998; Testa et al., 1998), which corresponds to that of mGluRla and mGluR5 proteins (Houamed et al., 1991; Abe et al., 1992; Minakami et al., 1993). The specificity of both antibodies was further tested in our laboratory by immunoblot analysis on proteins isolated from transfected cell lines and specific rat and monkey brain regions (Marino et al., 2001) (M. Kuwajima, R. A. Hall, and Y. Smith, unpublished data). In keeping with previous findings, both the mGluRla and mGluR5 antibodies were found to be highly specific for their corresponding antigens and did not show any significant cross-reactivity between each other when tested on transfected cells. The anti-mGluRla antiserum specifically labeled a band at $\sim 140 \mathrm{kDa}$ in lanes containing proteins from cells expressing mGluRla but not from cells expressing mGluR5; the converse was seen with the mGluR5 antiserum (Marino et al., 2001) (Kuwajima, Hall, and Smith, unpublished data). Both antibodies labeled a band corresponding to the approximate molecular weight of mGluRla and mGluR5 in monkey brain tissue. Furthermore, the use of mGluR5 antibodies on homogenates of striatal tissue from mGluR5 knock-out mice did not reveal any band labeling (Kuwajima, Hall, and Smith, unpublished data). Consistent with previous studies performed using different highly specific group I mGluRs antibodies (Romano et al., 1995; Petralia et al., 1997), cerebellar homogenates did not display any significant labeling for mGluR5, but expressed mGluR1a labeling. Preabsorption of antibodies with their corresponding peptides $(10 \mu \mathrm{g} / \mathrm{ml}$ homologous peptides for 1 $\mathrm{hr}$ at room temperature) abolished specific labeling. Together, these observations strongly indicate that both antisera used in the present study are highly specific for their corresponding proteins in rat and monkey brain tissue.

Single mGluR1a and mGluR5 immunoperoxidase labeling for light microscopy. The sections were preincubated for $1 \mathrm{hr}$ in $10 \%$ normal horse serum (NHS), $1 \%$ bovine serum albumin (BSA), and 0.3\% Triton X-100 (TX) in PBS before being incubated overnight at room temperature (RT) with primary antibodies (mGluR1a, $0.5 \mu \mathrm{g} / \mathrm{ml}$; mGluR5, $1.0 \mu \mathrm{g} / \mathrm{ml}$ ) mixed in the antibody diluent ( $1 \%$ NHS, $1 \%$ BSA, and $0.3 \%$ TX in PBS). After rinsing with PBS, the sections were incubated for $1.5 \mathrm{hr}$ in a solution of secondary antibodies (1:200; biotinylated goat anti-rabbit IgGs; Vector Laboratories, Burlingame, CA), rinsed in PBS, and incubated $1.5 \mathrm{hr}$ in the avidin-biotin peroxidase complex (ABC) (1:100; Vector Laboratories). The sections were then washed in PBS and Tris buffer $(0.05 \mathrm{M} ; \mathrm{pH}$ 7.6) before being transferred to a solution containing $0.025 \% 3,3^{\prime}$ diaminobenzidine tetrahydrochloride (DAB) (Sigma, St. Louis, MO), $0.01 \mathrm{~m}$ imidazole (Sigma), and $0.005 \%$ hydrogen peroxide for $10 \mathrm{~min}$. The sections were then washed in PBS, mounted on gelatin-coated slides, and dehydrated, and a coverslip was applied with Permount.

Single preembedding immunoperoxidase and immunogold labeling for $m$ GluR1a and $m$ GluR5 at the electron-microscopic level. All of the sections prepared for electron microscopy were placed in a cryoprotectant solution ( $0.05 \mathrm{M} \mathrm{PB}, \mathrm{pH} 7.4$, containing $25 \%$ sucrose and $10 \%$ glycerol), frozen at $-80^{\circ} \mathrm{C}$, thawed, and returned to a graded series of cryoprotectant and PBS. Sections processed for immunoperoxidase were incubated the same way as for light microscopy, except that no TX was used in the antibody diluent, and the incubation in the primary antibodies lasted $48 \mathrm{hr}$ at $4^{\circ} \mathrm{C}$.

Sections used for immunogold labeling were processed the same way as those for electron-microscopic immunoperoxidase including the following modifications: (1) the antibody diluent was a PBS-BSA solution $(0.05 \%$ Tween $20,0.005 \%$ BSA, and $0.001 \%$ gelatin in PBS), (2) the secondary antibodies were goat anti-rabbit Fab' fragments conjugated to $1.4 \mathrm{~nm}$ gold particles (1:100; Nanogold; Nanoprobes, Stony Brook, NY), and (3) after incubation in the secondary antibodies and washes in PBS$\mathrm{BSA}$, sections were fixed for $10 \mathrm{~min}$ in $1 \%$ glutaraldehyde and rinsed with $\mathrm{PB}$, and the gold particles were silver intensified for 6-12 min with the HQ silver kit (Nanoprobes).

All of the sections for electron microscopy were then treated with $1 \%$ osmium tetroxide in PB for 10 min (immunogold) or 20 min (immunoperoxidase), and dehydrated in a graded series of alcohol and propylene oxide. Uranyl acetate (1\%) was added to the $70 \%$ ethanol to enhance contrast. Sections were embedded with epoxy resin (Durcupan, ACM; Fluka, Buchs, Switzerland) for $12 \mathrm{hr}$, mounted on microscope slides, and put in the oven at $60^{\circ} \mathrm{C}$ for $48 \mathrm{hr}$. Samples of striatum were cut out from the slides, glued on the top of resin blocks with cyanoacrylate glue, and cut in 60-nm-thick ultrathin sections with an ultramicrotome (Ultracut T2; Leica, Nussloch, Germany). The ultrathin sections were collected on single-slot copper grids, stained with lead citrate (Reynolds, 1963) for 5 min, and examined with a Zeiss (Thorwood, NY) EM-10C electron microscope.

\section{Double labeling for tyrosine hydroxylase and group I $m$ GluRs}

A series of sections from the striatum in three monkeys were processed for electron-microscopic double immunostaining to reveal tyrosine hydroxylase (TH) and group I mGluRs. For this double-labeling procedure, sections were incubated overnight at RT with a mixture of mouse antityrosine hydroxylase (TH; 1:1000; Incstar, Stillwater, MN) and mGluR1a or mGluR5 antibodies in 1\% NHS-PBS-BSA. Then, they were incubated for $1.5 \mathrm{hr}$ in a mixture of biotinylated horse anti-mouse IgGs (1:200; Vector Laboratories) and $1.4 \mathrm{~nm}$ gold particle-conjugated goat antirabbit IgGs (1:100; Nanoprobes) in 1\% NHS-PBS-BSA. The gold particles used to localize mGluR immunoreactivity were then silver intensified as described above. Afterward, sections were washed in PB and incubated for $1.5 \mathrm{hr}$ in a 1:100 ABC solution. This was followed by washes in $\mathrm{PB}$ and Tris buffer before a $10 \mathrm{~min}$ incubation in $\mathrm{DAB}$ (see above) to localize TH. After many washes in PB, sections were processed for electron microscopy as described above for single labeling.

As controls, the $\mathrm{TH}$ or mGluR antibodies were omitted in turn from the incubation solution, whereas the rest of the procedure remained the same. This resulted in a lack of labeling corresponding to the omitted antibodies (i.e., the tissue was devoid of DAB staining in the absence of $\mathrm{TH}$ antibodies, whereas omission of the mGluR1a or mGluR 5 antibodies 

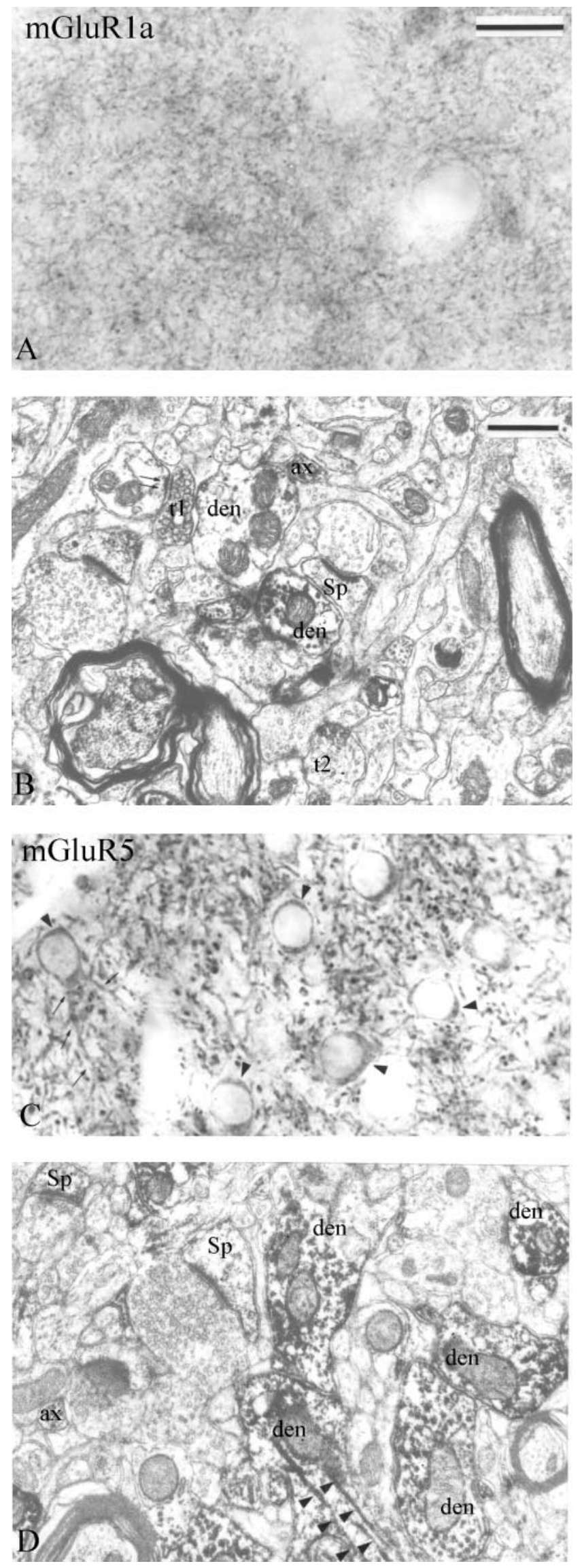

Figure 1. Immunoperoxidase labeling of group I mGluRs in the monkey striatum. $A, B$, Light and electron micrographs of mGluR1a immunostaining are shown. $A$, A dense mGluR1a-

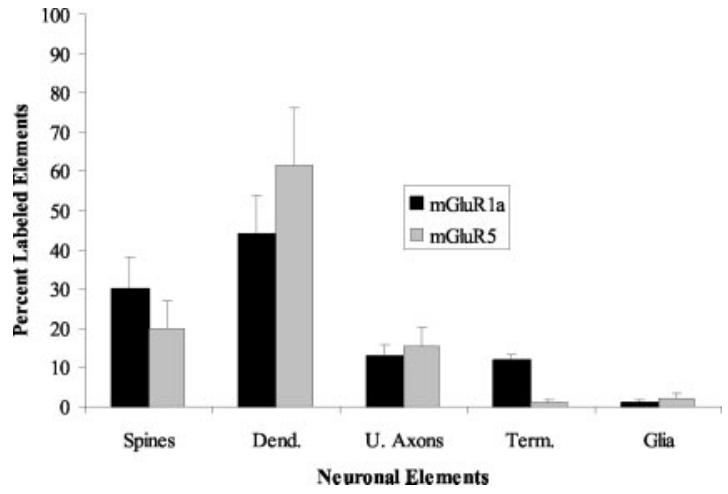

Figure 2. Histogram comparing the relative distribution of mGluR1a and mGluR5 immunoperoxidase labeling in different neuronal compartments and glia in the monkey striatum. Data are expressed as the mean percentage ( \pm SD) of labeling from three monkeys. Note the substantial difference in the relative abundance of mGluR1a-versus mGluR5-containing terminals. Total number $(n)$ of labeled elements examined from three monkeys: mGluR1a, 367; mGluR5, 476. Dend., Dendrites; U., unmyelinated; Term., terminals. Error bars indicate SD.

resulted in a complete lack of gold-particle labeling). Double-labeled elements were not found in any of these control sections.

\section{Tract-tracing studies combined with group I} mGluR immunostaining

Tracer injections and perfusion. Two adult squirrel monkeys (Saimiri sciureus) were used for this part of the study. The animals were first tranquilized with ketamine hydrochloride ( $10 \mathrm{mg} / \mathrm{kg}$, i.m.), intubated, and anesthetized with isoflurane before being fixed in a stereotaxic frame. These experiments were performed in strict accordance with the National Institutes of Health Guide for the Care and Use of Laboratory Animals and were approved by the Institutional Animal Care and Use Committee at Emory University. One monkey received bilateral iontophoretic injection of biotin-dextran-amine (BDA) $5 \%$ in distilled water; Molecular Probes, Eugene, OR) in the primary motor cortex, whereas the other animal was injected bilaterally in the centromedian (CM) thalamic nucleus. To perform these injections, BDA was loaded in glass micropipettes with a tip diameter of $20-30 \mu \mathrm{m}$. Then, it was injected iontophoretically with a $7 \mu \mathrm{A}$ positive current for $20 \mathrm{~min}$ using a $7 \mathrm{sec}$ on/off cycle. The stereotaxic coordinates were chosen according to the atlas of Emmers and Akert (1963). After $10 \mathrm{~d}$ survival, the animals were deeply anesthetized with an overdose of sodium pentobarbital $(100 \mathrm{mg} / \mathrm{kg}$, i.v.) and perfused transcardially with a cold Ringer's solution followed by fixative as described above. Sections from the same animals have been used previously for the study of kainate receptor localization in the striatum (Kieval et al., 2001). The thalamic injection sites were confined to $\mathrm{CM}$ with slight contamination of the overlying mediodorsal nucleus and the subparafascicular nucleus, whereas the cortical injections mostly involved the leg and trunk areas of M1 (for details, see Kieval et al., 2001).

Histochemical localization of BDA combined with group I mGluRs immunostaining. After perfusion, the brains were taken from the skull, cut in $60-\mu \mathrm{m}$-thick sections, put in cryoprotectant, and incubated overnight in $\mathrm{ABC}$ followed by a $10 \mathrm{~min}$ incubation in $\mathrm{DAB}$ to reveal BDA. Then, sections were processed to localize mGluRla or mGluR5 using the

\footnotetext{
$\leftarrow$

immunoreactive neuropil composed of small punctate elements is depicted. $B$, Dark DAB reaction product is observed in small dendrites (den), dendritic spines (Sp), unmyelinated axons (ax), and axon terminals (t). Note the mGluR1a-positive axon terminal (t1) forming an asymmetric axodendritic synapse (double arrows). The synaptic specialization of another labeled bouton (t2) cannot be determined. C, D, Light and electron micrographs of mGluR5 immunostaining. C, Immunoreactive cell bodies (arrowheads) and proximal dendrites (small arrows) of medium-sized projection neurons embedded into a dense meshwork of labeled processes. $D$, mGluR5-immunoreactive spines (Sp), dendrites (den), and axons (ax) are depicted. Note the dense mGluR5 immunoreactivity associated with microtubules (arrowheads). Scale bars: (in $A$ ) $A, C, 25 \mu \mathrm{m}$; (in $B) B, D, 0.5 \mu \mathrm{m}$.
} 
preembedding immunogold procedure (see above). This was followed by osmium postfixation, embedding in resin, and ultrathin sectioning for electron-microscopic observations.

Control experiments. As controls, sections were incubated in solutions from which one of the primary antisera or the $\mathrm{ABC}$ was omitted, whereas the rest of the procedure remained the same. Sections processed this way were completely devoid of gold particles when the mGluR antibodies were omitted or lacked any $\mathrm{DAB}$ staining after omission of $A B C$.

To control for nonspecific silver intensification of the peroxidase deposit (Liposits et al., 1984,1986 ) generated by the $\mathrm{ABC}$ reaction, two sections of postcommissural putamen that contained dense anterograde labeling from $\mathrm{CM}$ were processed according to the same protocol as described above, except that the immunogold localization of mGluRla was performed first, followed by the histochemical $\mathrm{ABC}$ reaction to visualize BDA. The overall pattern of single and double labeling generated by this approach was the same as that resulting from the original protocol, which demonstrates the reliability and high degree of specificity of this method. Together with results collected from the first series of control experiments, these observations demonstrate that colocalized $\mathrm{DAB}$ and immunogold deposits in anterogradely labeled terminals is a clear indicator of genuine presynaptic expression of group I mGluRs in thalamic and cortical boutons.
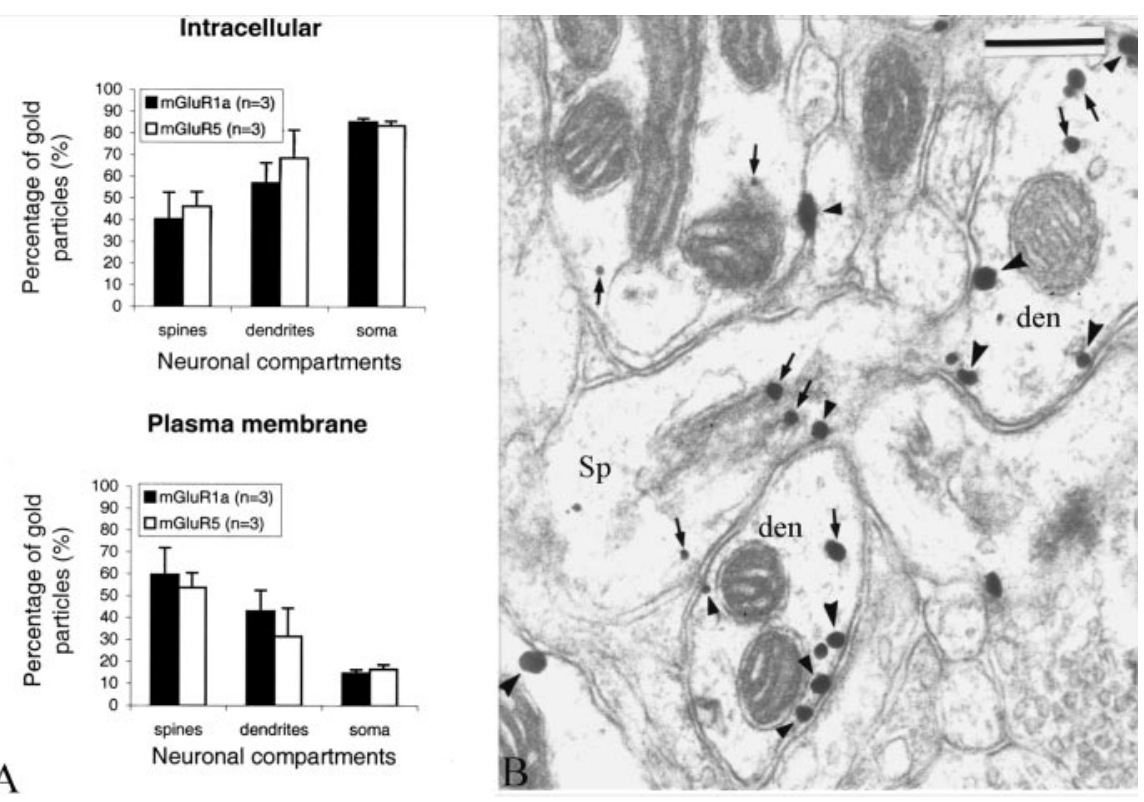

A

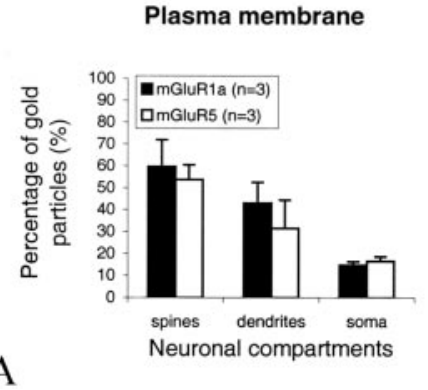

Figure 3. Intracellular and plasma membrane-apposed group I mGluR immunogold labeling in the monkey striatum. $A$, Relative proportion of intracellular versus plasma membrane-apposed immunogold particles for group I mGluRs in different neuronal compartments of striatal neurons. Mean values ( \pm SD) from three animals $(n)$ were used. A two-factor ANOVA did not reveal any significant difference between the distribution of mGluR1a and mGluR5 in the different neuronal compartments. The numbers of gold particles $(\mathrm{g})$ and neuronal elements (e) examined in three animals were as follows: mGluR1a spines, 665 (g) and 408 (e); mGluR5 spines, 891 (g) and 405 (e); mGluR1a dendrites, 1966 (g) and 744 (e); mGluR5 dendrites, 5526 (g) and 843 (e); mGluR1a soma, $3579(\mathrm{~g})$ and $71(\mathrm{e})$; and mGluR5 soma, $6111(\mathrm{~g})$ and 25 (e). Error bars indicate SD. B, Electron micrograph showing examples of mGluR1a-containing dendrites (den) and spines (Sp). Some intracellular and plasma membrane-apposed gold particles are indicated by small arrows and arrowheads, respectively. den, Dendrites; Sp, dendritic spines. Scale bar, $0.25 \mu \mathrm{m}$.

\section{Analysis of material}

Immunoperoxidase labeling for group I $m$ GluRs. The immunoperoxidase data were collected and quantified from a total of six blocks (three for mGluR1a; three for mGluR5) of striatal tissue from three rhesus monkeys. Serial ultrathin sections taken from the surface of the blocks were examined, and a series of 30 electron micrographs of randomly selected immunoreactive elements were shot at 20,000 $\times$. A total surface of 659 $\mu \mathrm{m}^{2}$ of striatal tissue was examined for each receptor subtype. The labeled elements were then categorized as spines, dendrites, unmyelinated axons, axon terminals, or glia on the basis of ultrastructural features described by Peters et al. (1991). The mean percentages of labeled elements were then calculated for each receptor subtype and expressed in a bar histogram (see Fig. 2).

Immunogold labeling for group I mGluRs. The immunogold data were gathered from a total of 27 blocks ( 14 for mGluR1a; 13 for mGluR5) of striatal tissue from five monkeys (three rhesus monkeys and two squirrel monkeys). Ultrathin sections from the surface of the blocks where the labeling was optimal were examined under the electron microscope, and randomly selected immunoreactive elements were photographed at low $(10,000 \times)$ and high $(25,000-31,500 \times)$ magnifications. Postsynaptic immunoreactive elements were categorized as spines, dendrites, and soma on the basis of ultrastructural features (Peters et al., 1991). Initially, quantitative measurements of gold-particle distribution in neuronal cell bodies were pooled into two main categories on the basis of the ultrastructural features of the nuclear membrane in labeled perikarya: neuronal somata containing nuclei with a smooth membrane and scarce cytoplasm were considered to be medium-sized projection neurons, whereas perikarya with a deeply invaginated nucleus and large cytoplasm were categorized as interneurons (DiFiglia et al., 1980; Graveland and DiFiglia, 1985). However, because no difference in the relative abundance of intracellular versus plasma membrane-apposed gold particles was found between these two major striatal cell types, data gathered from both neuronal populations were pooled for the final quantitative analysis presented in this study (see Fig. 3).

Gold particles were designated as plasma membrane apposed if they were in direct contact with the plasma membrane. All of the other gold particles were categorized as intracellular. On the basis of their localization relative to synapses, plasma membrane-apposed gold particles were further categorized as follows: (1) extrasynaptic, if they were in contact with parts of the plasma membrane located $>20 \mathrm{~nm}$ away from the edges of symmetric or asymmetric postsynaptic specializations, or (2) synaptic, if they were either in the main body or $\leq 20 \mathrm{~nm}$ away from the edges of synaptic specializations. On the basis of localization and the types of synapses with which it was associated, the synaptic labeling was pooled into four major groups: (1) asymmetric synapse-perisynaptic, if the gold particles were located $<20 \mathrm{~nm}$ away from the edges of asymmetric postsynaptic specializations, (2) asymmetric synapse-active zone, if gold particles were located in the main body of asymmetric postsynaptic specializations, (3) symmetric synapse-perisynaptic, if gold particles were located $<20 \mathrm{~nm}$ away from the edges of symmetric postsynaptic specializations, and (4) symmetric synapse-active zone, if the gold particles were located in the main body of symmetric postsynaptic specializations. Spines, dendrites, soma, and axon terminals that were poorly preserved or cut in a plane that was not suitable to distinguish the presynaptic and postsynaptic membranes were not considered in this analysis.

TH-mGluR double labeling. Analysis of the relationships between THcontaining terminals and group I mGluR labeling was performed as follows: ultrathin sections collected from double-immunostained striatal tissue were scanned in the electron microscope for the presence of THcontaining terminals located in the close vicinity of immunogoldcontaining striatal elements. Such terminals were photographed, and the relationships with presynaptic and postsynaptic gold particles were determined. A TH-positive terminal containing more than three gold particles was considered double labeled. To ascertain the specificity of the double labeling, putative double-labeled boutons were examined through serial ultrathin sections. In cases in which the postsynaptic elements contacted by the TH-positive boutons displayed mGluR immunoreactivity, the localization of the gold labeling relative to the postsynaptic specializations was determined and categorized as synaptic or extrasynaptic on the basis of the criteria described above. 
$B D A-m G l u R$ double labeling. The analysis of this material was done the same way as for the TH-mGluRs sections (i.e., the sections were scanned for BDA-containing boutons in close vicinity of mGluRcontaining elements). Once such a terminal was found, it was examined through serial sections for the presence of presynaptic or postsynaptic group I mGluRs associated with it. The postsynaptic labeling was categorized as synaptic or extrasynaptic on the basis of the criteria described above.

The distance between extrasynaptic gold-particle labeling for mGluR5 and the edges of putative glutamatergic synapses established by thalamostriatal and corticostriatal boutons was determined by scanning negatives of electron micrographs with a digital scanner (Powerlook II; UMAX, Fremont, CA) and then measuring the shortest distance between the center of the gold particles and the closest edge of the postsynaptic density of asymmetric synapses using the Neurolucida setup and Morph software (MicroBrightField, Colchester, VT).

Statistical analyses. All of the statistical analyses were performed using two-factor ANOVA with a Newman-Keuls post hoc analysis.

\section{Results}

\section{Light-microscopic observations}

At the light-microscopic level, the mGluRla antibody resulted in moderate striatal neuropil labeling that, at high magnification, was found to be mostly composed of numerous small punctate elements and beaded axon-like fibers (Fig. $1 \mathrm{~A}$ ). A small number of large, putative, striatal interneurons were also seen at various levels throughout the striatum (data not illustrated). In the mGluR5-immunostained tissue, the neuropil staining was intense and comprised large granular structures and dendritic processes coming off mGluR5-immunoreactive perikarya of putative projection neurons (Fig. $1 C$ ). Overall, the distribution of labeling with the two antisera was quite homogeneous throughout the striatum. No obvious patch-matrix pattern of distribution was observed in the mGluR5-immunostained tissue, but areas of lower mGluRla labeling reminiscent of patches were seen in the caudate nucleus.

\section{Electron-microscopic observations}

\section{Immunoperoxidase labeling}

At the electron-microscopic level, the overall pattern of labeling for the two group I mGluRs was similar, but the intensity of labeling was stronger for mGluR5 than mGluR1a (Fig. 1 $B, D$ ). The immunoperoxidase reaction product was mostly found in postsynaptic elements including spines, dendrites, and perikarya of various sizes with smooth or indented nuclear membranes (Fig. $1 B, D$ ). In dendrites, dense immunoreactivity for both group I mGluR subtypes was associated with microtubules (Fig. $1 D)$, whereas in spines, the labeling was significantly less intense and rather diffuse (Fig. $1 B, D$ ). Although the peroxidase deposit occasionally aggregated along the plasma membrane, clear subsynaptic localization of labeling could not be determined in this material (Fig. 1B,D). A significant number of small unmyelinated axons were labeled with either of the antibodies, whereas immunoreactive axon terminals were seen almost exclusively in the mGluRla-immunostained tissue (Fig. $1 B$ ).

To compare the pattern of distribution of mGluR1a and mGluR5 immunoreactivity, we quantified the relative proportion of labeled presynaptic and postsynaptic neuronal elements and glial processes for either receptor subtype in sections of postcommissural putamen from three monkeys (Fig. 2). This analysis revealed a substantial difference in the proportion of mGluRlaand mGluR5-immunoreactive axon terminals (11 vs 1\%, respectively), but the pattern of labeling in dendrites, spines, unmyelinated axons, and glia was relatively similar for both receptor
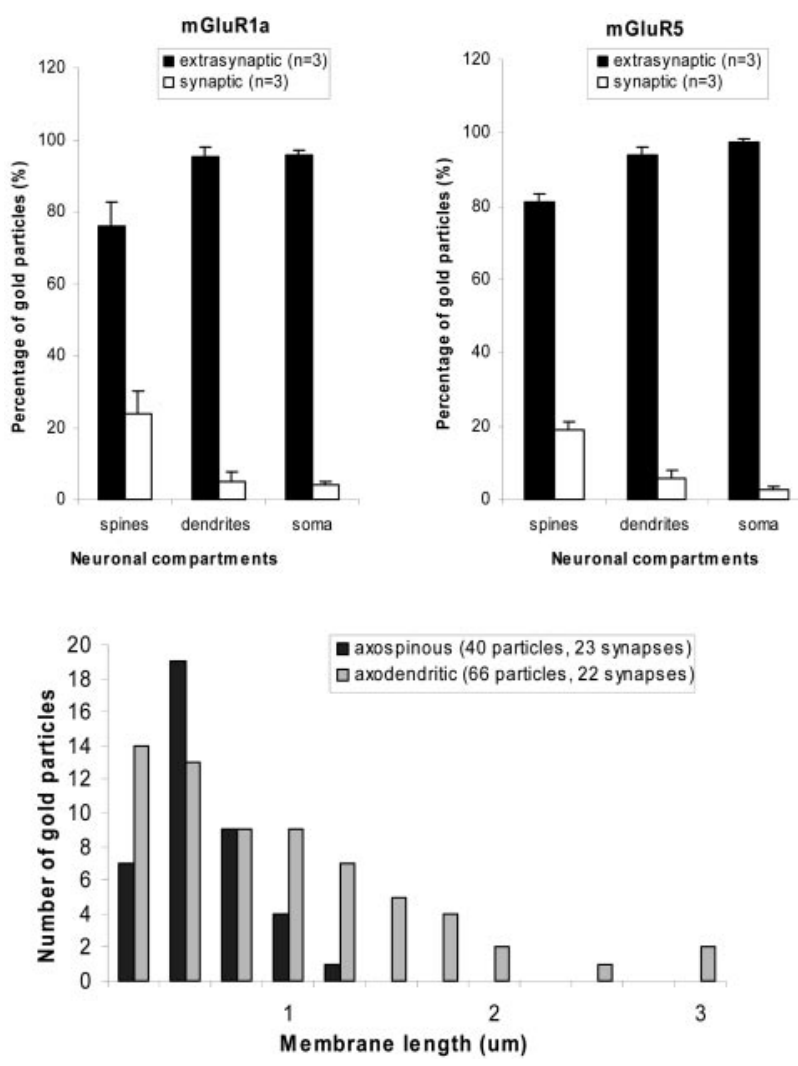

Figure 4. Extrasynaptic and synaptic plasma membrane-apposed group I mGluR immunogold labeling in the monkey striatum. $A$, Relative proportion of extrasynaptic versus synaptic plasma membrane-apposed gold particles for group I mGluRs in different compartments of striatal neurons. Mean values ( \pm SD) from three animals $(n)$ were used. The distribution of gold-particle labeling for either receptor subtype in spines was significantly different $(p<$ 0.05; ANOVA with post hoc Newman-Keul) from that in dendrites and soma. The total numbers of gold particles $(\mathrm{g})$ and neuronal elements (e) examined in three animals were as follows: mGluR1a spines, 419 (g) and 263 (e); mGluR5 spines, 465 (g) and 287 (e); mGluR1a dendrites, 892 (g) and 634 (e); mGluR5 dendrites, 1593 (g) and 843 (e); mGluR1a soma, 342 (g) and 70 (e); and mGluR5 soma, 1042 (g) and 25 (e). Error bars indicate SD. B, Distance between extrasynaptic plasma membrane-apposed gold-particle labeling for mGluR5 and the closest edge of asymmetric postsynaptic specializations. Serial sections of asymmetric synapses established by anterogradely labeled boutons from the cortex and thalamus were used in this analysis. The total number of gold particles and synapses examined is indicated in parentheses. The axospinous synapses are established by cortical terminals, whereas axodendritic synapses involve thalamostriatal boutons. Note that the majority of gold particles are located $<0.5 \mu \mathrm{m}$ away from either population of putative glutamatergic synapses.

subtypes (Fig. 2). Most mGluRla-immunoreactive boutons formed asymmetric synapses and displayed the ultrastructural features of putative glutamatergic terminals (see Figs. $1 \mathrm{~B}, 8 \mathrm{~A}$ ), although a small proportion of labeled terminals that contained large pleomorphic vesicles and rarely formed clear synaptic contacts were also encountered. The exact source(s) of these immunoreactive boutons was further characterized using doublelabeling procedures (see below).

\section{Immunogold labeling}

Synaptic versus extrasynaptic postsynaptic labeling. Because the immunoperoxidase deposit is rather diffuse and does not offer enough spatial resolution to study fine synaptic localization of receptor proteins, we used the preembedding immunogold approach to characterize the subsynaptic localization of mGluR1a and mGluR5 in relation to specific synaptic inputs on striatal neurons. Overall, the pattern of distribution of immunogold labeling for mGluR1a and mGluR5 was consistent with the immu- 
noperoxidase observations (i.e., both group I mGluRs were primarily expressed in striatal postsynaptic elements such as soma, dendrites, and spines). In spite of a higher density of gold labeling for mGluR5, the subcellular and subsynaptic distribution of the two group I mGluR subtypes in spines, dendrites, and neuronal cell bodies was relatively similar (Figs. 3-5). In somata of both projection neurons $(n=23$ for mGluR1a; $n=25$ for mGluR5) and interneurons $(n=10$ for mGluRla; $n=4$ for mGluR5) or in dendrites, 60$80 \%$ of gold labeling for either receptor subtype was associated with intracellular organelles (endoplasmic reticulum, Golgi apparatus, endosome-like vesicles) and microtubules, whereas in spines, $50-60 \%$ of gold particles were apposed to the plasma membrane (Fig. $3 A$ ), and the intracellular particles were often attached to the spine apparatus (Fig. 3B).

More than $80 \%$ of plasma membraneapposed gold labeling for mGluRla and mGluR5 was found extrasynaptically (Fig. $4 A$ ). Most of the remaining particles were either perisynaptic to asymmetric axospinous postsynaptic specializations (Fig. $5 A, B)$ or in the main body of axodendritic symmetric synapses (Fig. $5 A, C$ ). On both dendrites and spines, the largest density of plasma membrane-apposed gold-particle labeling for mGluR5 was found in the proximity $(<0.5 \mu \mathrm{m})$ of asymmetric synapses (Fig. $4 B$ ).

Perisynaptic labeling of corticostriatal and thalamostriatal synapses. To characterize the origin(s) of presynaptic afferents associated with postsynaptic group I mGluRs, we combined the anterograde transport of BDA from the primary motor cortex and CM [for details on the localization of injection sites, see Kieval et al. (2001), their Fig. 8] with the preembedding immunogold localization of mGluRla and mGluR5 (Fig. 6). After such injections, the pattern of immunogold labeling in relation to asymmetric synapses established by anterogradely labeled boutons was analyzed through serial sections. Overall, mGluR1a and mGluR5 displayed a similar pattern of distribution in relation to corticostriatal $(n=37)$ and thalamostriatal $(n=42)$ boutons. Approximately $25 \%$ of asymmetric synapses established by either type of putative glutamatergic terminals were labeled perisynaptically for mGluR1a (corticostriatal, 23.7\%; thalamostriatal, 26.8\%) or mGluR5 (corticostriatal, 24\%; thalamostriatal, 23.9\%). In some cases, the perisynaptic labeling could be seen through three to seven serial sections (Fig. 6). None of these synapses showed labeling in the main body of their active zones.

Perisynaptic labeling of dopaminergic synapses. As described above, a significant amount of postsynaptic labeling for mGluR1a and mGluR5 was also found in the main body or at the edges of symmetric postsynaptic specializations (Figs. $5 A, C, 7 A$ ). One of the main sources of terminals forming symmetric synapses in the monkey striatum is dopaminergic nigrostriatal axons (Smith et al., 1994). This, combined with the evidence of functional interactions between dopamine receptors and group I mGluRs in the

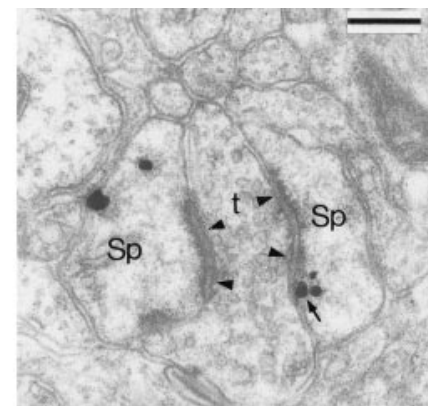

B

Asymmetric synapse-perisynaptic Asymmetric synapse-active zone Symmetric synapse-perisynaptic Symmetric synapse-active zone
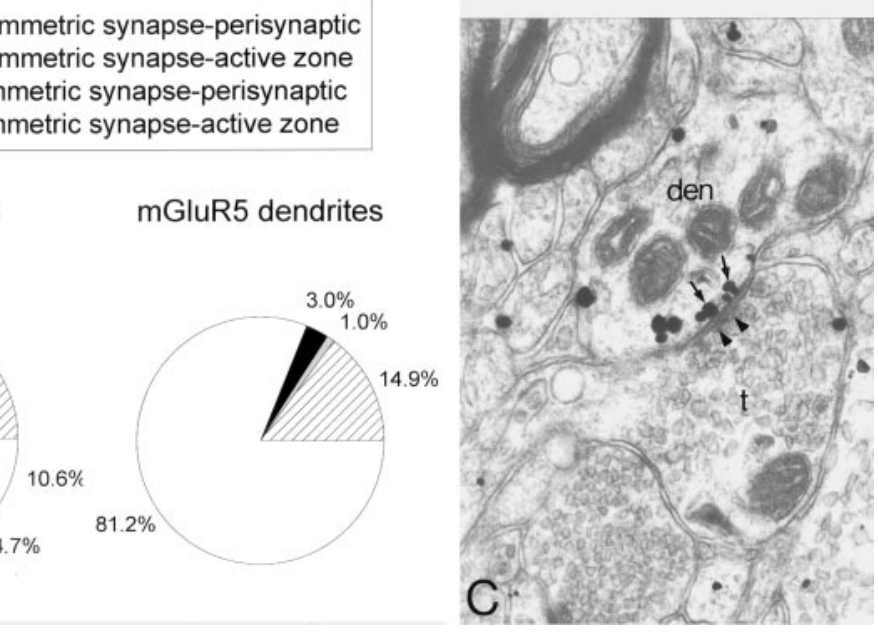

mGluR5 dendrites

Figure 5. Distribution of synaptic (perisynaptic vs active-zone) plasma membrane-apposed group I mGluR immunogold la(e). B, An example of perisynaptic gold-particle labeling for mGluR1a (arrow) at an axospinous asymmetric synapse (arrowheads). C, An example of gold-particle labeling for mGluR5 (arrows) apposed to the active zone of an axodendritic symmetric synapse (arrowheads). Sp, Spines; den, dendrites; t, axon terminals. Scale bar: (in B) B, C, $0.25 \mu \mathrm{m}$.

striatum (Calabresi et al., 1996, 2000), led us to test whether mGluR1a or mGluR5 immunogold labeling displayed any particular postsynaptic association with the synapses established by $\mathrm{TH}$-containing boutons in the striatum. Among the $53 \mathrm{TH}-$ positive boutons that formed symmetric synapses on mGluR5containing dendrites, $71 \%$ showed perisynaptic mGluR5 labeling (Fig. $7 \mathrm{~B}, \mathrm{C}$ ). In contrast, none of the $322 \mathrm{TH}$-immunoreactive boutons in contact with mGluRla-positive dendrites displayed perisynaptic labeling. Immunoreactivity for mGluRla and mGluR5 was never seen in the main body of dopaminergic synapses $(n=375)$.

Presynaptic labeling in glutamatergic and dopaminergic terminals. As mentioned above, a small proportion of immunoperoxidase labeling for mGluRla was found presynaptically in subpopulations of terminals forming asymmetric synapses (Figs. $1 B$, $2,8 A$ ). To test whether these boutons had a cortical or thalamic origin, we used striatal sections from animals injected with BDA in the primary motor cortex or CM (for location of injection sites, see Kieval et al., 2001) and determined whether the anterogradely labeled terminals in the postcommissural putamen displayed group I mGluR immunoreactivity. A total 177 anterogradely labeled boutons from CM and 96 from cortex were tested for coexpression of mGluR1a (122 from CM; 47 from cortex) or mGluR5 (55 from CM; 49 from cortex). Although the expression of group I mGluRs in all of the cortical boutons was tested in striatal sections processed to localize BDA first, 12 of the $122 \mathrm{CM}$ 

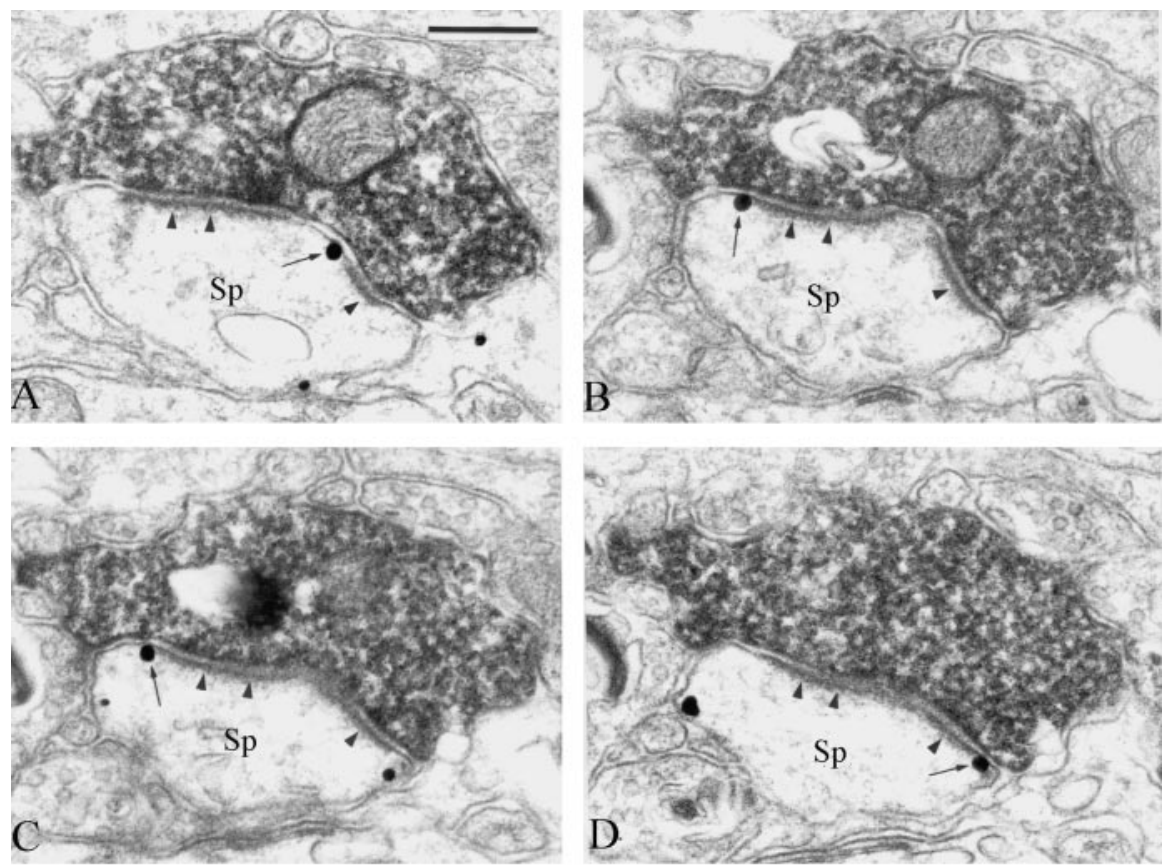

Figure 6. Serial ultrathin sections through perisynaptic mGluR5 immunoreactivity (arrows) at an asymmetric axospinous synapse (arrowheads) established by an anterogradely labeled cortical bouton. Note the high degree of specificity of the perisynaptic immunogold labeling in these sections. Sp, Dendritic spines. Scale bar: (in $A$ ), $A-D, 0.25 \mu \mathrm{m}$.

boutons tested for the expression of mGluR1a were collected from striatal sections processed first for the immunogold localization of mGluRla. Because no significant difference in the degree of single versus double labeling was found in these sections compared with others, data collected from both sets of sections were pooled.

As expected, on the basis of the immunoperoxidase data, very few cortical or thalamic boutons expressed mGluR5 immunoreactivity in double-immunostained sections (Fig. $8 D$ ). However, $\sim 40 \%$ of the thalamic boutons examined displayed mGluR1a immunolabeling ( 43 of 110 boutons processed for BDA first; 4 of 12 boutons processed for mGluRla first), whereas only $13 \%$ did so for mGluR5 (Fig. $8 B-D$ ). In contrast, $<10 \%$ of corticostriatal terminals displayed immunoreactivity for either of the receptor subtypes (Fig. 8C,D).

In sections immunostained for mGluRla, a second population of immunoreactive terminals contained large pleomorphic vesicles and rarely formed clear synaptic contacts when examined in single ultrathin sections. These ultrastructural features are reminiscent of either dopaminergic, GABAergic, or cholinergic terminals (Smith and Bolam, 1990; Smith et al., 1994). To further characterize the source of these boutons, we double immunostained striatal sections for TH and mGluR1a or mGluR5 (Fig. 9). This experiment revealed that $13 \%$ of the $522 \mathrm{TH}$-positive terminals examined displayed mGluRla immunoreactivity, which indicates that at least a small proportion of these mGluRlacontaining terminals arise from dopaminergic axonal projections (Fig. 9). As expected, on the basis of single immunoperoxidase data, double-labeled boutons were not found in sections immunostained for $\mathrm{TH}$ and mGluR5, which demonstrates the high degree of specificity of the double-labeling procedure used in the present study and further confirms that mGluRla, but not mGluR5, is expressed presynaptically in striatal dopaminergic boutons (Fig. 9).

\section{Discussion}

Although both group I mGluRs have long been characterized in striatal neurons, very little is known about their respective functions and subsynaptic localization (Calabresi et al., 1996, 2000). Interestingly, recent data gathered from various basal ganglia nuclei, including the striatum, indicate that mGluR1 and mGluR5 mediate different functions whenever they are coexpressed in the same brain region (Valenti et al., 2002). However, the exact mechanisms that underlie these differential effects remain poorly understood and highly speculative because of the limited knowledge on the subsynaptic localization of group I mGluRs in the basal ganglia. Our study provides a solid anatomical framework for a better understanding of group I mGluR functions in the primate striatum. The main findings are the following. First, the two group I mGluR subtypes display a similar pattern of subcellular and subsynaptic localization in postsynaptic elements. A large proportion of both mGluRla and mGluR5 immunoreactivity is expressed intracellularly, whereas a substantial component of the plasma membrane-apposed labeling for both receptor subtypes is located either extrasynaptically or at the edges of asymmetric postsynaptic specializations of cortical or thalamic afferents. Second, the two group I mGluRs are also associated postsynaptically with nonglutamatergic synapses; both mGluRla and mGluR5 immunoreactivity is expressed in the main body of symmetric axodendritic synapses, whereas mGluR5, but not mGluR1a, is located perisynaptically at the edges of symmetric dopaminergic synapses. Third, presynaptic mGluRla is expressed in putative glutamatergic terminals, but preferentially in thalamostriatal over corticostriatal afferents. A subset of dopaminergic terminals also displays mGluR 1 a, but not mGluR5, immunoreactivity.

Our findings demonstrate that the two group I mGluRs are primarily located extrasynaptically along the plasma membrane of striatal neurons, a pattern of distribution consistent with that described for group I mGluRs in other basal ganglia nuclei (Hanson and Smith, 1999; Smith et al., 2000, 2001; Hubert et al., 2001). In fact, most G-protein-coupled receptors are located extrasynaptically throughout the CNS (Yung et al., 1995; Gracy et al., 1997; Rodriguez et al., 1999; Smith et al., 2000, 2001). This raises important questions about the mechanisms of activation and functions of these receptors in normal and pathological conditions. Regarding activation of mGluRs, various possibilities have been raised ranging from extrasynaptic spillover of glutamate to glia-neuron communication. Both glial and neuronal glutamate transporters appear to be critical in controlling the activation of presynaptic and postsynaptic mGluRs in various brain regions (Brasnjo and Otis, 2001; Oliet et al., 2001; Reichelt and Knopfel, 2002; Rusakov and Lehre, 2002). Although glutamate transporter functions have not been studied in great detail in the striatum, both the glial and neuronal transporters are abundantly expressed in this region (Charara et al., 2003), indicating that, indeed, they may control the rate of extrasynaptic diffusion of 

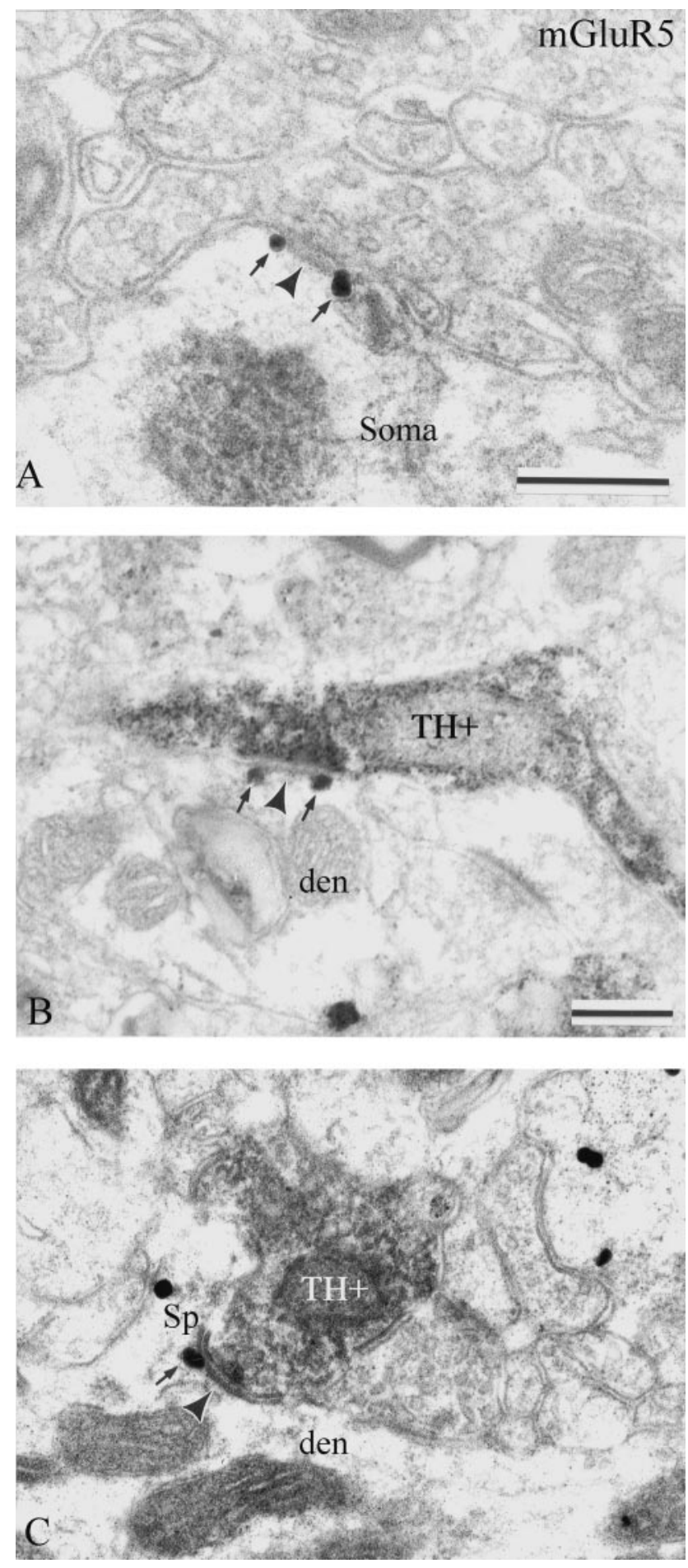

Figure 7. Postsynaptic mGluR5 immunoreactivity at dopaminergic synapses in the monkey striatum. $A$, Two perisynaptic gold particles (arrows) are associated with an en passant axosomatic symmetric synapse (arrowheads) established by an axonal process that displays the ultrastructural features of a dopaminergic nigrostriatal terminal. $B, C$, Examples of perisynaptic labeling for mGluR5 (arrows) at dopaminergic synapses. In $B$, the TH-positive axonal process $(\mathrm{TH}+)$ forms an en passant-type synaptic contact (arrowhead) with a dendrite (den), whereas in $C$, the TH-positive axon terminal ( $\mathrm{TH}+$ ) is in contact with a spine neck (Sp). Scale bars: $A, 0.25$ $\mu \mathrm{m} ;$ (in $B), B, C, 0.25 \mu \mathrm{m}$.

glutamate necessary to activate mGluRs. Interestingly, the expression of glial glutamate transporters in the striatum is increased in Huntington's disease or after bilateral cortical lesions, but not affected by thalamic lesion (Lievens et al., 2000). How- ever, glutamate reuptake decreases after cortical lesions but increases after thalamic lesions (Nieoullon et al., 1985; Lievens et al., 2000). Moreover, levodopa therapy in rodent models of Parkinson's disease results in a selective increase of GLT1 (glutamate transporter 1) expression in the striatum (Lievens et al., 2001). Assuming that activation of mGluRs in the striatum relies on proper functioning of glutamate transporters, one may speculate that mGluR-mediated effects may be directly or indirectly altered by manipulation and/or lesion of glutamatergic or dopaminergic striatal afferents. Experiments are currently in progress in our laboratory to elucidate the potential role of glutamate transporters in controlling activation of group I mGluRs in basal ganglia nuclei under normal and pathological conditions.

An interesting observation made in the present study is that of the presynaptic and postsynaptic localization of the two group I mGluRs at dopaminergic synapses. The fact that mGluR1 is located presynaptically, whereas mGluR5 is postsynaptic to dopaminergic synapses, emphasizes the specificity and potential differences in functional interactions between the two group I mGluRs and dopaminergic terminals. Although there is good evidence for the cooperation of mGluRs and dopamine to induce LTD of corticostriatal synapses in the rat striatum, the precise presynaptic and postsynaptic mechanisms and exact subtypes of mGluRs involved remain unclear (Calabresi et al., 2000). Our findings indicate that mGluR1 is located to subserve presynaptic modulatory effects on dopamine release, which is consistent with microdialysis findings showing that local application of group I mGluR agonists facilitates dopamine release in the rat striatum (Verma and Moghaddam, 1998; Bruton et al., 1999). Although group I mGluRs are commonly seen as postsynaptic receptors, they also mediate presynaptic autoreceptor or heteroreceptor inhibitory functions in various basal ganglia nuclei (Awad-Greko and Conn, 2001; Marino et al., 2001; Wittmann et al., 2001). The use of specific group I mGluR antagonist is essential to further characterize the potential functions of presynaptic mGluR1 in striatal dopaminergic terminals.

Another way through which dopamine and glutamate may interact is via activation of postsynaptic mGluR5 located perisynaptically to dopaminergic synapses. One possibility is that mGluR5 and dopamine receptors cooperate to induce striatal LTD by convergence on common signaling pathways to regulate intracellular calcium levels. Such a mechanism was recently proposed for the induction of LTD in the cerebral cortex (Otani et al., 1999). Another possibility would be that mGluR5 and dopamine receptors functionally interact via direct protein-protein interactions, a phenomenon that has been characterized for other G-protein-coupled receptors in the CNS including dopamine and adenosine receptors with group I mGluRs (Ciruela et al., 2001; Popoli et al., 2001; Ferre et al., 2002). The fact that mGluR5 and dopamine receptors display a similar pattern of subsynaptic distribution relative to dopaminergic synapses (Yung et al., 1995) supports the possibility of functional interactions between these receptors. As discussed above, the source and mechanisms of activation of mGluR5 at nonglutamatergic synapses is likely to be very complex and relies on extrasynaptic diffusion of glutamate. However, it is worth noting that midbrain dopaminergic neurons express vesicular glutamate transporter mRNA (Fremeau et al., 2002) and possibly release glutamate in the striatum (Sulzer et al., 1998; Rayport, 2001). Therefore, the hypothesis that dopamine and glutamate may be coreleased at individual synapses in the striatum should be kept in mind while considering the potential source(s) of activation of presynaptic and postsynaptic group I mGluRs at dopaminergic synapses. Although the exact functional 

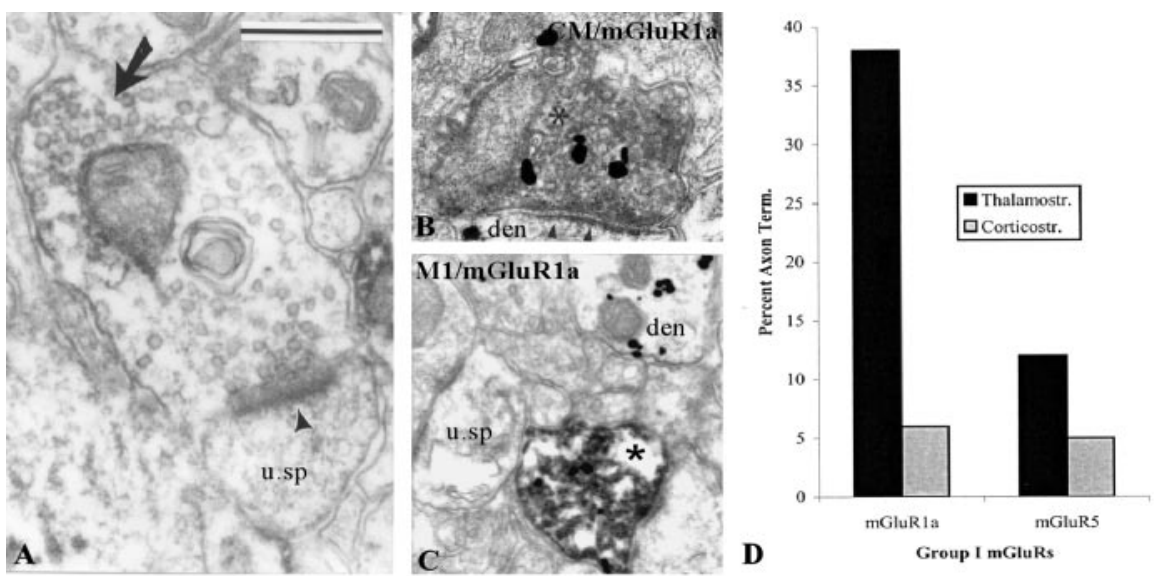

Figure 8. Presynaptic mGluR1a in putative glutamatergic terminals from the thalamus and cerebral cortex. $A$, Shown is a mGluR1a-containing terminal forming an asymmetric axospinous synapse (arrowhead). The peroxidase deposit is indicated by a large arrow. $B, C$, Depicted are thalamostriatal $(B)$ and corticostriatal ( $C$ BDA-labeled boutons (asterisks in $B$ and $C$ ) that express mGluR1a immunoreactivity (gold labeling) in the postcommissural putamen. In these micrographs, BDA has been revealed with DAB, whereas mGluR1a immunoreactivity is localized with gold particles. u. sp, Unlabeled spine; den, dendrite. Scale bars: (in $A$ ) $B, 0.5 \mu \mathrm{m} ; C, 0.8 \mu \mathrm{m}$. D, Histogram that compares the relative abundance of thalamostriatal and corticostriatal terminals that express mGluR1a immunoreactivity in the monkey putamen. Note the preponderance of presynaptic mGluR1a labeling in thalamostriatal boutons. Term., Terminals; Thalamostr., thalamostriatal; Corticostr., corticostriatal.
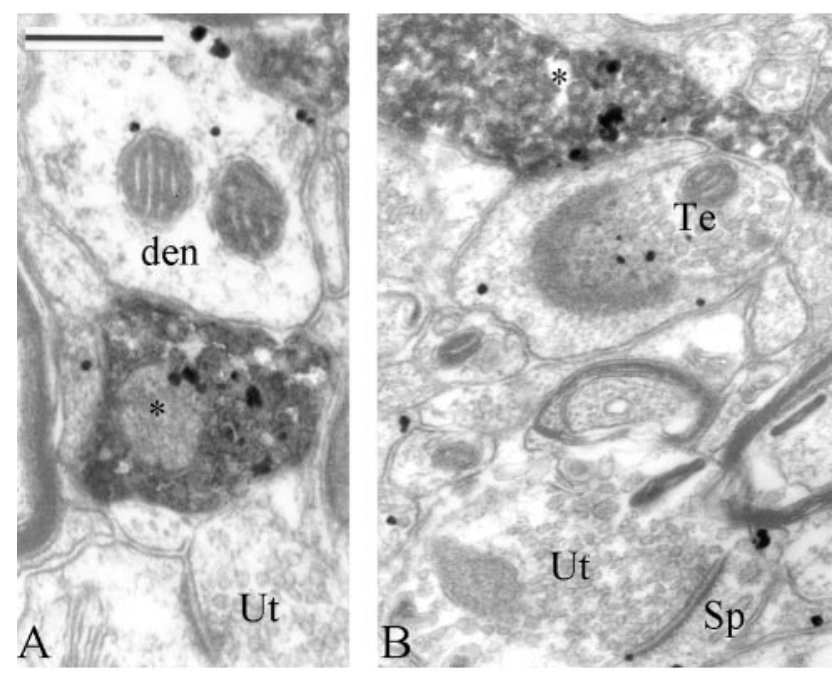

Figure 9. Presynaptic group I mGluR immunoreactivity in dopaminergic terminals (asterisks) in the monkey putamen. In these micrographs, TH is localized with the amorphous DAB reaction product, whereas mGluR1a is labeled with gold particles. A TH-negative bouton that expresses mGluR1a immunoreactivity (Te) is shown in $B$, and unlabeled terminals (Ut) for both TH and mGluR1a are indicated. den, Dendrites; Sp, dendritic spines. Scale bar: (in $A$ ), $A, B, 250 \mathrm{~nm}$.

significance of these anatomical observations remains to be determined, they provide additional evidence for complex receptor cross-talks and molecular cooperativity underlying synaptic plasticity.

Our data provide convincing evidence for presynaptic expression of mGluR1a in thalamostriatal boutons from CM and, although much less frequently encountered, in corticostriatal afferents. However, mGluR5 was rarely seen in either population of putative glutamatergic afferents. These observations suggest that group I mGluRs may mediate both presynaptic and postsynaptic functions at glutamatergic synapses in the monkey striatum. Presynaptic effects of group I mGluRs on excitatory neurotransmission have been shown in other basal ganglia nuclei including the subthalamic nucleus and substantia nigra pars reticulata, two brain regions in which mGluRla is found in unmyelinated axons and putative glutamatergic axon terminals (Awad et al., 2000; Wittmann et al., 2001). Activation of group I mGluRs also modulates presynaptic GABA release in the hippocampus, although recent evidence suggests that these effects may, in fact, be mediated by the retrograde signaling from endocannabinoid released by postsynaptic neurons (Varma et al., 2001). In the striatum, mGluR1, but not mGluR5, was found to modulate GABA release presynaptically (Battaglia et al., 2001), a rather surprising finding in consideration of our data showing that most of the mGluR1-immunoreactive terminals in the monkey striatum are either immunoreactive for $\mathrm{TH}$ or display the ultrastructural features of putative glutamatergic boutons. However, we cannot rule out the possibility that some of the mGluRla-immunoreactive terminals seen in the present study are GABAergic. For technical reasons inherent to the different fixation conditions necessary for optimal detection of group I mGluRs and GABA, we could not use postembedding immunogold labeling for GABA on this tissue. Together, these findings indicate that mGluR1 likely mediates presynaptic modulatory functions on GABA, glutamate, and dopamine release in the striatum. However, the exact physiological or pathological conditions under which these receptors may be activated remain to be established.

Data presented in this and previous studies show that a large proportion of group I mGluR labeling is located intracellularly in various neuronal populations of the basal ganglia (Hubert et al., 2001). In neurons of the substantia nigra pars reticulata, the two group I mGluRs display a strikingly different pattern of subcellular localization: mGluRla labeling is apposed to the plasma membrane, whereas $>80 \%$ of mGluR5 immunoreactivity is intracellular (Hubert et al., 2001). We could not detect any significant difference in the proportion of plasma membrane-apposed versus intracellular labeling for mGluRla and mGluR5 in the monkey striatum, suggesting that the regulation, trafficking, and possibly turnover of the two group I mGluRs subtypes differ from one brain region to another.

In conclusion, the findings of the present study provide various sites whereby activation of group I mGluRs could modulate synaptic transmission in the monkey striatum. The differential distribution of mGluR1a and mGluR5 at dopaminergic synapses opens up the possibility for complex protein-protein interactions that could play important roles in the induction and maintenance of long-term synaptic plasticity. Finally, the presynaptic and postsynaptic expression of group I mGluRs at thalamostriatal and corticostriatal synapses provides additional evidence for tight mGluR-mediated modulatory control of glutamatergic transmission in the primate striatum.

\section{References}

Abe T, Sugihara H, Nawa H, Shigemoto R, Mizuno N, Nakanishi S (1992) Molecular characterization of a novel metabotropic glutamate receptor mGluR5 coupled to inositol phosphate/Ca ${ }^{+2}$ signal transduction. J Biol Chem 267:13361-13368.

Awad H, Hubert GW, Smith Y, Levey AI, Conn PJ (2000) Activation of metabotropic glutamate receptors has direct excitatory effects and poten- 
tiates NMDA receptor currents in neurons of the subthalamic nucleus. J Neurosci 20:7871-7879.

Awad-Greko H, Conn PJ (2001) Activation of groups I and III metabotropic glutamate receptors inhibits excitatory transmission in the rat subthalamic nucleus. Neuropharmacology 41:32-41.

Battaglia G, Bruno V, Pisani A, Centonze D, Catania MV, Calabresi P, Nicoletti F (2001) Selective blockade of type-1 metabotropic glutamate receptors induces neuroprotection by enhancing GABAergic transmission. Mol Cell Neurosci 17:1071-1083.

Bradley SD, Standaert DG, Rhodes KJ, Reese HD, Testa CM, Levey AI, Conn PJ (1999) Immunohistochemical localization of subtype 4a metabotropic glutamate receptors in the rat and mouse basal ganglia. J Comp Neurol 407:33-46.

Brasnjo G, Otis TS (2001) Neuronal glutamate transporters control activation of postsynaptic metabotropic glutamate receptors and influence cerebellar long term depression. Neuron 31:607-616.

Bruton R, Ge J, Barnes NM (1999) Group I mGlu receptor modulation of dopamine release in the rat striatum in vivo. Eur J Pharmacol 19:175-181.

Calabresi P, Pisani A, Mercuri NB, Bernardi G (1996) The corticostriatal projection: from synaptic plasticity to basal ganglia disorders. Trends Neurosci 19:19-24.

Calabresi P, Centonze D, Gubellini P, Marfia GA, Pisani A, Sancessario G, Bernardi G (2000) Synaptic transmission in the striatum: from plasticity to neurodegeneration. Prog Neurobiol 61:231-265.

Charara A, Paquet M, Rothstein JD, Smith Y (2003) Subcellular and subsynaptic localization of glutamate transporters in the monkey basal ganglia. In: The basal ganglia VI (Graybiel AM, DeLong MR, Kitai ST, eds), pp 599-614. New York: Kluwer Academic/Plenum.

Ciruela F, Escriche M, Burgueno J, Angulo E, Casado V, Soloviev MM, Canela EI, Mallol J, Chan W-Y, Lluis C, Mcilhinney RAJ, Franco R (2001) Metabotropic glutamate 1a and adenosine A1 receptors assemble into functionally interacting complexes. J Biol Chem 276:18345-18351.

Conn JP, Pin J-P (1997) Pharmacology and functions of metabotropic glutamate receptors. Annu Rev Pharmacol Toxicol 37:205-237.

Corti C, Aldegheri L, Somogyi P, Ferraguti F (2002) Distribution and synaptic localization of the metabotropic glutamate receptor 4 (mGluR4) in the rodent CNS. Neuroscience 110:403-420.

DiFiglia M, Pasik T, Pasik P (1980) Ultrastructure of Golgi-impregnated and gold-toned spiny and aspiny neurons in the monkey striatum. J Neurocytol 9:471-492.

Emmers R, Akert S (1963) A stereotaxic atlas of the brain of the squirrel monkey (Saimiri sciureus). Madison, WI: University of Wisconsin.

Ferraguti F, Conquet F, Corti C, Grandes P, Kuhn R, Knopfel T (1998) Immunohistochemical localization of the mGluR $1 \beta$ metabotropic glutamate receptor in the adult rodent forebrain: evidence for a differential distribution of mGluR1 splice variants. J Comp Neurol 400:391-407.

Ferre S, Karcz-Kubicha M, Hope BT, Popoli P, Burgueno J, Gutierrez MA, Casado V, Fuxe K, Goldberg SR, Lluis C, Franco R, Ciruela F (2002) Synergistic interaction between adenosine A2A and glutamate mGlu5 receptors: implications for striatal neuronal function. Proc Natl Acad Sci USA 99:11940-11945.

Fremeau Jr RT, Burman J, Qureshi T, Tran CH, Proctor J, Johnson J, Zhang H, Sulzer D, Copenhagen DR, Storm-Mathisen J, Reimer RJ, Chaudhry FA, Edwards RH (2002) The identification of vesicular glutamate transporter 3 suggests novel modes of signaling by glutamate. Proc Natl Acad Sci USA 99:14488-14493.

Gracy KN, Svingos AL, Pickel VM (1997) Dual ultrastructural localization of $\mu$-opioid receptors and NMDA-type glutamate receptors in the shell of the rat nucleus accumbens. J Neurosci 17:4839-4848.

Graveland GA, DiFiglia M (1985) The frequency and distribution of medium-sized neurons with indented nuclei in the primate and rodent striatum. Brain Res 327:307-311.

Gubellini P, Saulle E, Centonze D, Bonsi P, Pisani A, Bernardi G, Conquet F, Calabresi P (2001) Selective involvement of mGlu1 receptors in corticostriatal LTD. Neuropharmacology 40:839-846.

Hanson JE, Smith Y (1999) Group I metabotropic glutamate receptors at GABAergic synapses in monkeys. J Neurosci 19:6488-6491.

Houamed KM, Kuijper JL, Gilbert TL, Haldeman BA, O’Hara PJ, Mulvihill ER, Almers W, Hagen FS (1991) Cloning, expression, and gene structure of a $\mathrm{G}$ protein-coupled glutamate receptor from rat brain. Science 252:1318-1321.

Hubert GW, Paquet M, Smith Y (2001) Differential subcellular localization of mGluR1a and mGluR5 in the rat and monkey substantia nigra. J Neurosci 21:1838-1847.

Kieval JZ, Hubert GW, Charara A, Pare J-F, Smith Y (2001) Subcellular and subsynaptic localization of presynaptic and postsynaptic kainate receptor subunits in the monkey striatum. J Neurosci 21:8746-8757.

Kinoshita AR, Shigemoto R, Ohishi H, Van der Putten H, Mizuno N (1998) Immunohistochemical localization of metabotropic glutamate receptors, mGluR7a and mGluR7b, in the central nervous system of the adult rat and mouse: a light and electron microscopic study. J Comp Neurol 393:332-352.

Kosinki CM, Bradley SR, Conn PJ, Levey AI, Landwehrmeyer GB, Penney Jr JB, Young AB, Standaert DG (1999) Localization of metabotropic glutamate receptor $7 \mathrm{mRNA}$ and mGluR7a protein in the rat basal ganglia. J Comp Neurol 415:266-284.

Lievens JC, Salin P, Had-Aissouni L, Mahy N, Kerkerian-Le Goff L (2000) Differential effects of corticostriatal and thalamostriatal deafferentation on expression of the glutamate transporter GLT1 in the rat striatum. J Neurochem 74:909-919.

Lievens JC, Salin P, Nieoullon A, Kerkerian-Le Goff L (2001) Nigrostriatal denervation does not affect glutamate transporter mRNA expression but subsequent levodopa treatment selectively increases GLT1 mRNA and protein expression in the rat striatum. J Neurochem 79:893-902.

Liposits Z, Setalo G, Flerko B (1984) Application of the silver-gold intensified 3,3'-diaminobenzidine chromogen to the light and electron microscopic detection of the LH-RH system of the rat brain. Neuroscience 13:513-525.

Liposits Z, Phelix C, Paull WK (1986) Adrenergic innervation of corticotropin releasing factor (CRF)-synthesizing neurons in the hypothalamic paraventricular nucleus of the rat. A combined light and electron microscopic immunocytochemical study. Histochemistry 84:201-205.

Marino MJ, Wittmann M, Bradley SR, Hubert GW, Smith Y, Conn PJ (2001) Activation of group I metabotropic glutamate receptors produces a direct excitation and disinhibition of GABAergic projection neurons in the substantia nigra pars reticulata. J Neurosci 21:7001-7012.

Minakami R, Katsuki F, Sugiyama H (1993) A variant of metabotropic glutamate receptor subtype 5: an evolutionally conserved insertion with no termination codon. Biochem Biophys Res Commun 194:622-627.

Nakanishi S (1994) Metabotropic glutamate receptors: synaptic transmission, modulation, and plasticity. Neuron 13:1031-1037.

Nieoullon A, Scarfone E, Kerkerian L, Errami M, Dusticier N (1985) Changes in choline acetyltransferase, glutamic acid decarboxylase, highaffinity glutamate uptake and dopaminergic activity induced by kainic acid lesion of thalamostriatal neurons. Neurosci Lett 58:299-304.

Oliet SH, Piet R, Poulain DA (2001) Control of glutamate clearance and synaptic efficacy by glial coverage of neurons. Science 292:923-926.

Otani S, Auclair N, Desce J-M, Roisin M-P, Crepel F (1999) Dopamine receptors and groups I and II mGluRs cooperate for long-term depression induction in rat prefrontal cortex through converging postsynaptic activation of MAP kinases. J Neurosci 19:9788-9802.

Paquet M, Smith Y (2000) Subsynaptic localization of group I metabotropic glutamate receptors at glutamatergic synapses in the monkey striatum. Soc Neurosci Abstr 26:740.13.

Peters A, Palay SL, Webster HF (1991) The fine structure of the nervous system-neurons and their supporting cells, Ed 3. New York: Oxford UP.

Petralia RS, Wang Y-X, Singh S, Wu C, Shi L, Wei J, Wenthold RJ (1997) A monoclonal antibody shows discrete cellular and subcellular localizations of mGluR $1 \alpha$ metabotropic glutamate receptors. J Chem Neuroanat 13:77-93.

Pisani A, Gubellini P, Bonsi P, Conquet F, Picconi B, Centonze D, Bernardi G, Calabresi P (2001) Metabotropic glutamate receptor 5 mediates the potentiation of $N$-methyl-D-aspartate responses in medium spiny striatal neurons. Neuroscience 106:579-587.

Popoli P, Pezzola A, Torvinen M, Reggio R, Pintor A, Scarchilli L, Fuxe K, Ferre S (2001) The selective $\mathrm{mGlu}_{5}$ receptor agonist CHPG inhibits quinpirole-induced turning in 6-hydroxydopamine-lesioned rats and modulates the binding characteristics of dopamine $\mathrm{D}_{2}$ receptors in the rat striatum: interactions with adenosine $\mathrm{A}_{2 \mathrm{a}}$ receptors. Neuropharmacology 25:505-513.

Rayport S (2001) Glutamate is a cotransmitter in ventral midbrain dopamine neurons. Parkinsonism Relat Disord 7:261-264.

Reichelt W, Knopfel T (2002) Glutamate uptake controls expression of a 
slow postsynaptic current mediated by mGluRs in cerebellar Purkinje cells. J Neurophysiol 87:1974-1980.

Reynolds ES (1963) The use of lead citrate at high $\mathrm{pH}$ is an electron opaque stain in electron microscopy. J Cell Biol 17:208-212.

Rodriguez JJ, Garcia DR, Pickel VM (1999) Subcellular distribution of 5-hydroxydopamine $2 \mathrm{~A}$ and $\mathrm{N}$-methyl-D-aspartate receptors within single neurons in rat motor and limbic striatum. J Comp Neurol 413:219-231.

Romano C, Sesma MA, McDonald CT, O’Malley K, Van den Pol AN, Olney JW (1995) Distribution of metabotropic glutamate receptor mGluR5 immunoreactivity in rat brain. J Comp Neurol 355:455-469.

Rusakov DA, Lehre KP (2002) Perisynaptic asymmetry of glia: new insights into glutamate signaling. Trends Neurosci 25:492-494.

Smith AD, Bolam JP (1990) The neural network of the basal ganglia as revealed by the study of synaptic connections of identified neurons. Trends Neurosci 13:259-265.

Smith Y, Bennett BD, Bolam JP, Parent A, Sadikot AF (1994) Synaptic relationships between dopaminergic afferents and cortical or thalamic input in the sensorimotor striatum in monkey. J Comp Neurol 344:1-19.

Smith Y, Charara A, Hanson JE, Paquet M, Levey AI (2000) GABA and group I metabotropic glutamate receptors in the striatopallidal complex in primates. J Anat 196:555-576.

Smith Y, Charara A, Paquet M, Kieval JZ, Pare J-F, Hanson JE, Hubert GW, Kuwajima M, Levey AI (2001) Ionotropic and metabotropic GABA and glutamate receptors in primate basal ganglia. J Chem Neuroanat 22:13-42.

Sulzer D, Joyce MP, Lin L, Geldwert D, Haber SN, Hattori T, Rayport S (1998) Dopamine neurons make glutamatergic synapses in vitro. J Neurosci 18:4588-4602.

Sung K-W, Choi S, Lovinger DM (2001) Activation of group I mGluRs is necessary for induction of long-term depression at striatal synapses. J Neurophysiol 86:2405-2412.

Tamaru Y, Nomura S, Mizuno N, Shigemoto R (2001) Distribution of metabotropic glutamate receptor mGluR3 in the mouse CNS: differential location relative to pre- and postsynaptic sites. Neuroscience 106:481-503.

Testa CD, Standaert DG, Young AB, Penney JB Jr (1994) Metabotropic glutamate receptor mRNA expression in the basal ganglia of the rat. J Neurosci 14:3005-3018.

Testa CD, Standaert DG, Landwehrmeyer GB, Penney JB, Young AB (1995) Differential expression of mGluR5 metabotropic glutamate receptor mRNA by rat striatal neurons. J Comp Neurol 354:241-252.

Testa C, Friberg IK, Weiss SW, Standaert DG (1998) Immunohistochemical localization of metabotropic glutamate receptors mGluRla and mGluR2/3 in the rat basal ganglia. J Comp Neurol 390:5-19.

Valenti O, Conn PJ, Marino MJ (2002) Distinct physiological roles of the $\mathrm{G}_{\mathrm{q}}$-coupled metabotropic glutamate receptors co-expressed in the same neuronal populations. J Cell Physiol 191:125-137.

Varma N, Carlson GC, Ledent C, Alger BE (2001) Metabotropic glutamate receptors drive the endocannabinoid system in hippocampus. J Neurosci 21:RC188(1-5).

Verma A, Moghaddam B (1998) Regulation of striatal dopamine release by metabotropic glutamate receptors. Synapse 28:220-226.

Wittmann M, Hubert GW, Smith Y, Conn PJ (2001) Activation of metabotropic glutamate receptor 1 inhibits glutamatergic transmission in the substantia nigra pars reticulata. Neuroscience 105:881-889.

Yung KKL, Bolam JP, Smith AD, Hersch SM, Ciliax BJ, Levey AI (1995) Immunocytochemical localization of D1 and D2 dopamine receptors in the basal ganglia of the rat: light and electron microscopy. Neuroscience 65:709-730. 